\title{
Effects of "Langoy sa Kaluwasan- Learn to Swim" Extension Project to the Swimming Competency of Barangay Emergency Response Personnel
}

\author{
Edilberto A. Artiga Jr. $\mathrm{II}^{1}$, Charis B. Limbo ${ }^{1, *}$, Lyndon L. Maningo ${ }^{1}$, Leo A. Mamolo ${ }^{2}$ \\ ${ }^{1}$ Institute of Human Kinetics, College of Education, Visayas State University, Visca, Baybay City, Leyte, Philippines \\ ${ }^{2}$ VSU Integrated High School, College of Education, Visayas State University, Visca, Baybay City, Leyte, Philippines
}

Received October 7, 2020; Revised November 11, 2020; Accepted December 13, 2020

\section{Cite This Paper in the following Citation Styles}

(a): [1] Edilberto A. Artiga Jr. II, Charis B. Limbo, Lyndon L. Maningo, Leo A. Mamolo, "Effects of "Langoy sa Kaluwasan- Learn to Swim" Extension Project to the Swimming Competency of Barangay Emergency Response Personnel," International Journal of Human Movement and Sports Sciences, Vol. 8, No. 6, pp. 438 - 443, 2020. DOI: 10.13189/saj.2020.080616.

(b): Edilberto A. Artiga Jr. II, Charis B. Limbo, Lyndon L. Maningo, Leo A. Mamolo (2020). Effects of "Langoy sa Kaluwasan- Learn to Swim" Extension Project to the Swimming Competency of Barangay Emergency Response Personnel. International Journal of Human Movement and Sports Sciences, 8(6), 438 - 443. DOI: 10.13189/saj.2020.080616.

Copyright $@ 2020$ by authors, all rights reserved. Authors agree that this article remains permanently open access under the terms of the Creative Commons Attribution License 4.0 International License

\begin{abstract}
Swimming is an essential skill, especially to the barangay emergency response teams near lakes, rivers, and beaches. It is a skill intended not only for recreation and livelihood but as preparation for unforeseen water emergencies. Acquiring this skill may help prevent drowning incidents that can lead to death. This research aims to determine whether the "Langoy sa Kaluwasan-Learn to Swim" extension project improved and developed the swimming skills of thirteen (13) barangay emergency response personnel in Baybay City, Leyte, Philippines. It utilized an experimental research design, specifically a one-group Pretest-posttest Research Design. The experiment took five weeks duration conducted at the Visayas State University (VSU) beach resort. Results showed that the participants' swimming competency is Satisfactory before the project and enhanced to Outstanding after the project. Results further affirmed the significant increase of the participants swimming competency with the help of the extension project. The results implied that although the participants are the barangay emergency response personnel of their barangays, they still had a lot to improve, especially in the different swimming skills, namely, bubbling, floating, gliding, direction change, water-treading, underwater swim, and freestyle. With these enhanced skills, they will
\end{abstract}

also be expected to teach children and the youth of their respective barangays the skills they have learned. Thus, the national government may structure similar training capacitating and improving the barangay emergency response teams' skills to respond appropriately in calamities and unforeseen water emergencies.

Keywords Swimming, Barangay Emergency Response Personnel, Competency

\section{Introduction}

Swimming is an activity or a sport of propelling oneself through water using the limbs [1]. It is an essential skill not just because it is good for health but also because it can save lives. It is intended not only for recreation and livelihood but as preparation for unforeseen water emergencies as well.

The importance of swimming cannot be taken lightly, considering the drowning incidents happening every year worldwide. Drowning is the result of breathing impairment due to immersion in a liquid and not being able to swim [2]. A World Health Organization Global Study reports that 
drowning is a public health epidemic that kills 372,000 people annually, $90 \%$ of whom come from low and middle-income countries such as the Philippines [3].

Filipinos exposure to bodies of water undeniably cost their lives because the Philippines is archipelagic. The country is most exposed to tropical storms in the world [4]. One major cause of drowning is bad weather [5], and most drownings occurred within the cyclone seasons. As a result, each year, too many Filipinos lose their lives due to drowning. According to a United Nations Children's Fund survey, drowning is reportedly the fourth leading cause of death in the Philippines. What makes these deaths even more tragic is that they are nearly always preventable [6]. Furthermore, the International Life Saving (ILS) [7] noted that "evidence is rapidly accumulating that a basic level of water safety knowledge, coupled with a basic level of swimming skill, is sufficient to prevent most drowning episodes."

Capacitating the Barangay Emergency Response Personnel towards disaster awareness and preparedness can help lessen drowning incidents in the country caused by tropical storms and other similar calamities. Members of the Barangay Emergency Response Personnel are individuals who are under the supervision of the Barangay Disaster Risk Reduction and Management Council (BDRRMC). Their functions are described in the Philippine Disaster Risk and Reduction Management (PDRRM) Act of 2020 [8]. Equipping the personnel to acquire the necessary skills in swimming and water rescue and basic first aid is essential to increase their awareness level and enhance their capacity to the threats and impacts of all hazards. It is also one way to mitigate the adverse effects of climate change and to lessen casualties. It is also an assurance that the barangay can be equipped with the skills and manage disaster-related stresses through survival swimming skills.

The need for competent barangay emergency response personnel's awareness and preparedness is already apparent. However, their competency to respond to emergencies must be established. Understanding the level of competency in swimming skills is of paramount importance as one qualification to becoming barangay emergency response personnel. Moreover, swimming competency is one of the necessary skills that can reduce drowning in any individual. This includes skills like entry and exit in bodies of water, controlling breathing, floating, turning, and moving to safety in the water and exiting. Assessing the barangay emergency response personnel's swimming competency can be a starting point for assessing minimum swim skills for typical pool environments [9]. This will further determine the readiness of the appointed emergency response personnel in each BDRRMC. This is another step to assess the personnel's overall basic swimming skills and perform an intervention to improve their skills.

This study aims to determine if the "Langoy sa Kaluwasan- Learn to Swim" extension project improved and capacitated the 13 barangay emergency response personnel of Baybay City, Leyte, Philippines.

Specifically, this study sought to answer the following:

1. What is the participants' swimming competency before the "Langoy sa Kaluwasan-Learn to Swim" extension project/experiment?

2. What is the participants' swimming competency after the "Langoy sa Kaluwasan-Learn to Swim" extension project/experiment?

3. Is there a significant difference in the participants' swimming competency before and after the extension project/experiment?

\section{Materials and Methods}

\subsection{Research Design}

This research utilized an experimental research design, specifically a one-group Pretest-posttest Research Design. The experimental research design is concerned with examining the effect of the independent variable on the dependent variable. The independent variable is manipulated through treatment or intervention(s), and the effect of those interventions is observed on the dependent variable [10]. In the study, only one group was given an intervention. The swimming instructor rated the swimming competency of the participants before and after the intervention.

\subsection{Research Participants}

At the beginning of the extension program, there were 21 participants, but only 13 of them finished the experiment's 5-week duration. The final list of participants consisted of two Females and 11 Males. The age ranged from 18 to 57 years old. The high range of participants' age is because BDRRMC appointed barangay emergency response personnel who are fit for the role, not too young nor senior citizens. The participants came from the six barangays of Baybay City, Leyte, Philippines, namely, Gabas, Guadalupe, Pangasugan, Marcos, San Agustin, and Bunga. The participants were barangay emergency response personnel under the supervision of the BRRMC of their respective barangays.

\subsection{Research Locale}

The 5-week extension project was conducted at the Visayas State University (VSU) beach resort. The researchers are instructors at the Institute of Human Kinetics (IHK) of this university.

\subsection{Research Instrument}

A checklist tool was utilized in rating the participants' swimming competency before and after the extension 
project/experiment. This instrument is a 5-point scaling system where the swimming instructors checked on the corresponding competency a participant acquired. The checklist includes swimming skills: Bubbling, Floating, Gliding, Direction Change, Water Treading, Underwater Swim, and Freestyle. The utilized instrument was validated by experts in swimming and two Ed. D. experts in Physical Education from the Institute of Human Kinetics.

The table below shows the scores, description, and interpretation of the participants' swimming competency. Experts in swimming and Physical education validated the instrument with the following interpretation.

Table 1. Score Ranges, Description, and Interpretation of Participants' Swimming Competency

\begin{tabular}{|c|c|c|}
\hline Score & Description & Interpretation \\
\hline $4.51-5.0$ & Outstanding & $\begin{array}{l}\text { Instructors believed the participants } \\
\text { to have } 91-100 \% \text { mastery of the } \\
\text { swimming competency. }\end{array}$ \\
\hline $3.51-4.50$ & $\begin{array}{c}\text { Very } \\
\text { Satisfactory }\end{array}$ & $\begin{array}{l}\text { Instructors believed the participants } \\
\text { to have } 71-90 \% \text { mastery of the } \\
\text { swimming competency. }\end{array}$ \\
\hline $2.51-3.50$ & Satisfactory & $\begin{array}{l}\text { Instructors believed the participants } \\
\text { to have } 41-70 \% \text { mastery of the } \\
\text { swimming competency. }\end{array}$ \\
\hline $1.51-2.50$ & Fair & $\begin{array}{l}\text { Instructors believed the participants } \\
\text { to have } 21-40 \% \text { mastery of the } \\
\text { swimming competency. }\end{array}$ \\
\hline $1.00-1.50$ & Poor & $\begin{array}{l}\text { Instructors believed the participants } \\
\text { to have } 0-20 \% \text { mastery of the } \\
\text { swimming competency. }\end{array}$ \\
\hline
\end{tabular}

\subsection{Limitations}

This extension project focuses only on the participants' swimming skills in Bubbling, Floating, Gliding, Direction Change, Water Treading, Underwater Swim, and Freestyle. Other strokes in swimming were not introduced due to the limited time intended for the project.

\subsection{Data Gathering Procedure}

In the conduct of the project/experiment, Langoy sa Kaluwasan- Learn to Swim, the Institute of Human Kinetics (IHK) Swimming Instructors gave the participants the outline of the activities in the conduct of the training. These instructors are experts on the field and are certified experienced swimming instructors, and varsity coaches. A lecture about it also took place. The IHK swimming instructors also did a Pre-Test on the skills of the participants. Also, they asked the participant to fill-up the Physical Activity Readiness Questionnaire (PAR-Q) and You to assess the medical conditions and physical limitations of the participants. The Body Mass Index (BMI) of the participants was also assessed to determine the participants' health and physical well-being.

The next step was the orientation phase on pool safety guidelines and the do's and don'ts before, during, and after the water activities. IHK has developed guidelines that helped to minimize preventable accidents or injury among participants to the greatest extent possible. Participants were also oriented on the proper progression of doing physical activities like swimming. This includes the proper way of stretching and warm-up exercise in a water environment conducted by one of the swimming instructors of IHK.

The lecture-demonstration and execution commenced on the 1st to the 5th Sunday of the training. All the participants were handled correctly by the swimming instructors with one instructor to 4 participants. They were given proper instructions on how to teach and to use their acquired competency to children.

On the 5th Sunday of the training, participants were tasked to bring a child aged six and above to teach the basics of the learn-to-swim project and were evaluated through the children's progress in a whole day session. This is one way of enhancing the swimming teams' role in informing children on health issues and accident prevention in water [11].

\subsection{Statistical Tools}

In determining the barangay emergency response personnel's swimming competency before and after the project/experiment, mean and standard deviation were employed. In determining the significant difference in the participants' swimming competency before and after the program, the Wilcoxon-signed Rank test was utilized.

\section{Results and Discussions}

Before the conduct of the project/experiment, it is noted that most of the participants have little knowledge of swimming. Table 2 shows the swimming competency of the barangay emergency response personnel. It is noted that they have a Satisfactory rating in the underwater swim $(M=3.69, S D=1.18)$, and it is their highest. However, the participants had hard time floating $(M=2.27, S D=0.86)$ and swimming freestyle $(M=2.00, S D=1.00)$. Overall, the barangay emergency response personnel have a Satisfactory swimming competency $(M=2.87, S D=1.09)$.

Table 2. Participants' Swimming Competency before the Extension Project

\begin{tabular}{cccc}
\hline Swimming Techniques & $\boldsymbol{M}$ & $\boldsymbol{S D}$ & Description \\
\hline Bubbling & 2.77 & 0.83 & Satisfactory \\
Floating & 2.27 & 0.86 & Fair \\
Gliding & 3.15 & 0.38 & Satisfactory \\
Direction Change & 2.85 & 0.55 & Satisfactory \\
Water Treading & 3.38 & 1.5 & Satisfactory \\
Underwater Swim & 3.69 & 1.18 & Very Satisfactory \\
Freestyle & 2 & 1 & Fair \\
Total & 2.87 & 1.09 & Satisfactory \\
\hline
\end{tabular}


The result of the study, as shown in table 2, disclosed that most of the participants were sinkers; that is why underwater swim is the highest. Because they were sinkers, it was easier for them to do underwater swim. The participants' bodies were also oriented in seawater, where buoyant force is far different from that of the pool water. It is easier to float in the seawater rather than in the pool water. These skills are aspects of buoyancy control [12]. Most of the participants were also adults with lean body mass, causing the body to sink in the water. Fatter people are more buoyant than skinnier ones, and that is because fat is less dense (more buoyant) than muscle [13]. The participants were also living in coastal areas where the primary source of living is fishing, including diving. Thus, they were confident in submerging themselves underwater.

On the contrary, the participant's floating skill is one of the lowest because, again, they were sinkers. Usually, both feet sink first, then the body follows; that is why it is difficult for the sinkers to remain afloat, especially in the pool water. It is essential to note that the reasons for drowning are most associated with failure to stay afloat [14]. Also, freestyle swimming stroke was the lowest because it is the most complex swimming skill introduced in the extension project. This skill utilizes all the basic swimming skills introduced. This stroke is more difficult to master than any other stroke [15].

After the conduct of the extension program, the participants had acquired an outstanding rating. Table 3 highlights that Bubbling got the highest rating in the six swimming techniques $(M=4.87, S D=0.22)$. Among the list, freestyle swimming stroke got a very satisfactory rating $(M=4.00, S D=1.00)$. Overall, the barangay emergency response personnel had an outstanding competency $(M=4.71, S D=0.56)$.

Table 3. Participants' Swimming Competency after the Extension Program

\begin{tabular}{cccc}
\hline Swimming Techniques & $\boldsymbol{M}$ & $\boldsymbol{S D}$ & Description \\
\hline Bubbling & 4.87 & 0.22 & Outstanding \\
Floating & 4.77 & 0.37 & Outstanding \\
Gliding & 4.85 & 0.24 & Outstanding \\
Direction Change & 4.77 & 0.44 & Outstanding \\
Water Treading & 4.85 & 0.38 & Outstanding \\
Underwater Swim & 4.85 & 0.38 & Outstanding \\
Freestyle & 4 & 1 & Very Satisfactory \\
Total & 4.71 & 0.56 & Outstanding \\
\hline
\end{tabular}

The results of the study show that bubbling is the highest. Most people know how to do the bubbling. This is what people usually perform when submerging their heads in any water environment [16] to acquire breath control and water confidence. Learning how to blow bubbles is the foundation for swimmers once they start learning swim strokes [17]. Bubbling is more on the control of breathing and water confidence. Because participants were already exposed to 5-week swimming exercises and activities, their breathing control has improved considerably. Add to that; swimming is good for cardiovascular endurance.

On the other hand, freestyle is still the lowest because of its complexity. The participant has already acquired prior knowledge of freestyle but inappropriately. It was not easy on the participant's side to correct how they perform the freestyle they got to practice since they were young, which is already a part of their muscle memory. Although there was an increase in the freestyle's performance, the participants still need to improve this skill. Swimming is a complex action, and it takes years to become comfortable with it.

After the project/experiment, a significant increase was recorded. Table 4 presents the Wilcoxon signed-rank test on the Significant Differences of the Swimming Competency of the Participants before and after the experiment. It is indicated that the swimming competency after the intervention was statistically significantly higher than of the participants' swimming competency before the intervention, $T=91, z=-3.180, p<0.005$.

Table 4. Wilcoxon Signed Rank Test on the Significant Differences of the Swimming Competency of the Participants before and after the experiment

\begin{tabular}{cccccc}
\hline $\begin{array}{c}\text { Swimming } \\
\begin{array}{c}\text { Competency } \\
\text { (Before and } \\
\text { After) }\end{array}\end{array}$ & $\mathrm{N}$ & $\begin{array}{c}\text { Mean } \\
\text { rank }\end{array}$ & $\begin{array}{c}\text { Total } \\
\text { rank }\end{array}$ & $\mathrm{z}$ & $\mathrm{p}$ \\
\hline Negative rank & 0 & 0.00 & 0.00 & -3.180 & $0.001^{*}$ \\
Positive rank & 13 & 7.00 & 91.00 & & \\
Equal & 0 & - & - & & \\
\hline
\end{tabular}

$*$ p-value $<0.005$

The increase in the swimming competency level among participants is attributed to the effectiveness of the extension project. It is similar to the study presented in the aerobic interval training in freestyle swimming, where participants' overall endurance and time increased after the training was conducted [18]. The participants' willingness to learn and improve their skills also helped in the level of improvement seen in this experiment. The participants already have prior knowledge of the skills; however, they did not know how to effectively and correctly perform the skills. Instructors believe that the critical part of their task is to reduce the faults of swimmers so that they swim "appropriately." [19].

Although the study participants were barangay emergency response personnel in barangays near beaches, rivers, and lakes, the participants' swimming competency before the extension project was fair and satisfactory. This could be affiliated with the communities' poor preparedness in selecting emergency response personnel. Similarly, in a study conducted by Kobusingye et al. [5], results showed high drowning rates and inadequate preparedness and responses by the communities and authorities. Further, learn-to-swim programs can 
accurately assess the swim skill of the population [20].

\section{Conclusions and Implications}

The study aimed to determine the swimming competency of the barangay emergency response personnel of Baybay City, Leyte, Philippines. Moreover, the experiment aimed to determine if the extension project entitled "Langoy sa Kaluwasan- Learn to Swim" has improved those participants' swimming competency in the 5 -week duration of the extension project. It was found out that before the extension project, the participants only had a satisfactory swimming competency. It has improved after the experiment in which they acquired an outstanding rating. Furthermore, a Wilcoxon signed-rank test affirmed the significant increase of the swimming competency of those who participated,

The results implied that although the participants are the barangay emergency response personnel of their barangays, they still had a lot to improve, especially in the different swimming skills, namely, bubbling, floating, gliding, direction change, water-treading, underwater swim, and freestyle. With these enhanced skills, they will also be expected to teach those who want to learn swimming skills. Thus, this extension project will give the barangay emergency response personnel the confidence to swim, teach how to swim, and save other people in times of water-related calamities.

The results may inform the national government of the need to consider such training in the different parts of the country. They may provide another set of training to every local government, especially those barangay emergency response personnel near lakes, rivers, and beaches. Furthermore, the results emphasized the need to design more effective and efficient programs to aid these people in times of need.

\section{Acknowledgments}

We are very grateful for the financial support provided by Visayas State University (VSU).

\section{REFERENCES}

[1] Introduction to swimming, Online available from https://www.checkfit.co.uk/introduction-to-swimming/

[2] A. Schmidt, J. Sempsrott, R. Zeigler, S. McAlister, \& M. Davison, The Use of Non-Utstein Style Drowning Terms since 2010: A Follow-up Study, World Conference in Drowning Prevention, Malaysia, 2015, Online available from https://www.ilsf.org/wp-content/uploads/2018/11/WC DP2015_ProgramProceedingsLR.pdf

[3] M. Linnan, The Level of Swimming Skill Necessary to
Protect Children in Laics from Drowning, World Conference on Drowning Prevention (WCDP), Malaysia, 2015, Online available from https://www.ilsf.org/wp-conten t/uploads/2018/11/WCDP2015_ProgramProceedingsLR.pdf

[4] A. Sebellino, 8 Filipinos die of drowning every day - DOH, 2011, Online available from http://verafiles.org/8-filipinosdie-of-drowning-every-day-doh/\#sthash.F9HYytJr.dpuf

[5] O. Kobusingye, N. Tumwesigye, L. Atuyambe, A. Hyder, \& O. Olange, Epidemiology of Drowning among Fishing Communities on the Shores of Lake Victoria in Uganda, World Conference in Drowning Prevention, Malaysia, 2015, Online available from https://www.ilsf.org/wp-content/uplo ads/2018/11/WCDP2015_ProgramProceedingsLR.pdf

[6] Philippine Drowning Prevention Plan, 2010, Online available from http://www.philippinelifesaving.org/filecabi net/PDPPlan2010-15Primer.pdf.pdr,2010=1015

[7] Basic Aquatic Survival Skill, 2012, International Life Saving Federation Lifesaving Position Statement, Online available from https://studylib.net/doc/7286320/lps-15-basi c-aquatic-survival-skill

[8] National Disaster Risk Reduction and Management Council, Department of the Interior and Local Government, Department of Budget and Management, Civil Service Commission, Joint Memorandum Circular No. 2014, Online available from bit.ly/ 2Hf7Xkz

[9] Water Safety USA, Become Water Competent, Online available from bit.ly/3dEQttA

[10] J. Patidar 2013, Writing Research Objectives, Online available from www.drjayeshpatidar.blogspot.com

[11] T. J. Terziadis, T. Rosenberg, V. Vichou, O. Routsi, Study of the Level of Knowledge and Awareness of Children in Greece During the First School Age (6-12 Years), In the Risk of Drowning and the Safe Behavior of Prevention and Treatment, World Conference on Drowning Prevention (WCDP), Malaysia, 2015, Online available from https://www.ilsf.org/wp-content/uploads/2018/11/WCDP20 15_ProgramProceedingsLR.pdf

[12] K. Moran, I Can Swim but Can I Get Out? The Exit Problem Explored, World Conference on Drowning Prevention (WCDP), Malaysia, 2015, Online available from https://www.ilsf.org/wp-content/uploads/2018/11/WCDP20 15_ProgramProceedingsLR.pdf

[13] C. Woodford, The Science of Swimming, 2020, Online available from https://www.explainthatstuff.com/swimming -science.html\#floating

[14] R.K. Stallman, Parallel Teaching: Maximizing Teaching Efficiency - Optimizing Learning Effect, World Conference on Drowning Prevention (WCDP), Malaysia, 2015, Online available fromhttps://www.ilsf.org/wp-content/uploads/201 8/11/WCDP2015_ProgramProceedingsLR.pdf

[15] Different Swimming Strokes and Their Benefits, Online available from https://allamericanswim.com/different-swim ming-strokes

[16] K. Tang, What Is Bubbling in Swimming?, Online available from bit.ly/ 2HhnpMH

[17] Blowing Bubbles - An Early Swim Skill, Online available fromhttps://www.seaotterswim.com/blowing-bubbles-an-ea 
rly-swim-skill

[18] Edi Wahyudi M, Yudi Hendrayana, Amung Ma’mun, Boyke Mulyana, "Aerobic Interval Training in Freestyle Swimming," International Journal of Human Movement and Sports Sciences, Vol. 8, No. 4, pp. 142 - 146, 2020. DOI: 10.13189/saj.2020.080406.

[19] R. Stallman, 2017, From Swimming Skill to Water Competence: A Paradigm Shift, International Journal of
Aquatic Research and Education: Vol. 10: No. 2, Article 2, Online available from http://scholarworks.bgsu.edu/ijare/vo 110/iss $2 / 2$

[20] E. Bennett, M. Crespo, L. Quan, J. Gilchrist, V. Levy, C. Williams, K. Wendorf, A. Gangan, \& R. Lee, Can You Really Swim? Study, World Conference on Drowning Prevention (WCDP). Malaysia, 2015, Online available from https://www.ilsf.org/wp-content/uploads/2018/11/WCDP20 15_ProgramProceedingsLR.pdf 